\title{
Be a Learning Organization - The Pilot Study of Organizations in the Czech Republic
}

\author{
Václav ZUBR \\ University of Hradec Králové, Hradec Králové, Czech Republic \\ vaclav.zubr@uhk.cz
}

\begin{abstract}
The learning organization model carries many benefits to organizations that apply it. The success of the transition to a learning organization can be controlled with the Dimensions of Learning Organization Questionnaire by Marsick and Watkins. Similarly, it is possible to determine with this questionnaire the stage of the learning organization. The aim of this study is to find out how many IT organizations in the Czech Republic apply the learning organization concept and to suggest ways to make effective and competitive organization (transition to a learning organization). The pilot study of 20 students (combined form of engineer study of Information Management) shows some interesting results. Most of the organizations achieved more than half points at the Likert scale. When comparing dimensions of learning organization between each other, there is a significant difference between some dimensions (dimension 2 vs. 3 and 6 vs. 7). We can say that Czech organizations are inclined to learn, and many of them apply the principles of learning organization in practice.
\end{abstract}

Keywords: Learning Organization, DLOQ, Learning Organization Benefits, Dimensions of Learning Organization.

\section{Introduction}

The concept of learning organization is beneficial for organizations, especially because it enables them to have more flexibility, competitiveness, achievement of wanted results as well as to survive longer then their rivals [5, 10]. Learning in organizations enables them to keep abreast with improvements in the business environment and developments [8]. Based on a continuous learning environment in a learning organization, the culture of learning organization has a positive impact on organizational performance and innovation [8, 12]. Due to this, it is better for organizations change to the learning organization. This transition to the learning organization is a difficult process when it is first necessary to find problem areas and causes that can create barriers to better results [3]. The goal is to achieve changes as long-term planning, strategic vision, teamworking, cooperation, communication, a positive attitude towards change and innovation etc. [3]. 


\subsection{Individual, Group and Organizational Learning}

In the typical learning organization, the learning is a part of organizational strategy. The individual learning is very important for organizations and learning at the individual level is completed in the development of the entire organization. It is necessary to point out that organizational learning is not a simple sum of individuals' learning. Crossan, Lane and White connect the importance of individual, group and organizational learning as a foundation for the entire organization. This claim is based on basic pillars: [1, 2, 9]

1. Organizational learning involves the tension between adaptation to new learning (exploration) and exploitation of already learned (exploitation).

2. Organizational learning takes place on several levels, individual, group and organizational.

3. These three levels are linked by socio-psychological processes: intuition, interpretation, integration and institutionalization (4I).

4. Cognition affects action and vice versa.

The model of learning organization that supports the Dimensions of Learning Organization Questionnaire highlights on the importance of continuous learning at the system level. The model highlights the continuous learning for teams and organizations. [4]

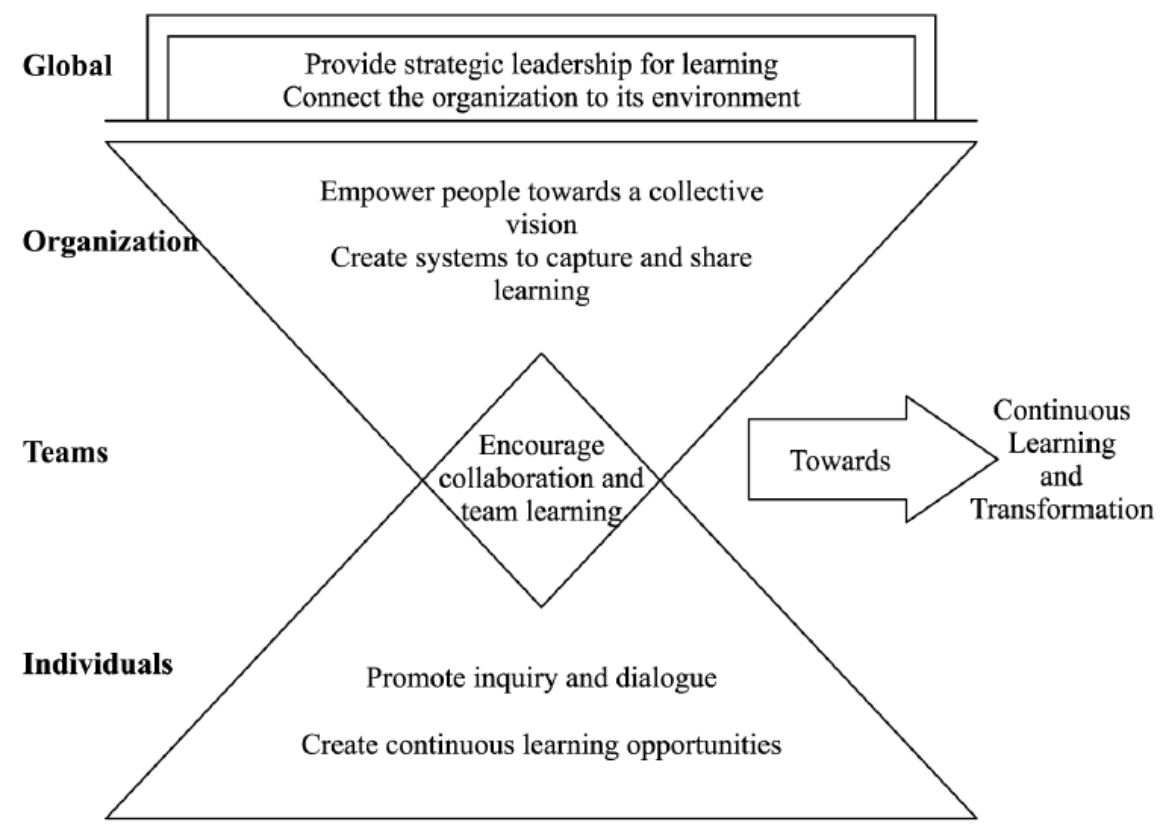

Fig. 1. Learning organization action imperatives [4] 


\subsection{Measurement of Learning Organization}

There are many tools for measurement and diagnostics of learning organizations, depending on the number of learning organization definitions. One of them is Marsick and Watkins definition of learning organization and their seven dimensions that characterize companies seeking to become learning organizations (Table 1). [4, 7]

Table 1. Definitions of Constructs for the Dimensions of the Learning Organization Questionnaire [7]

\begin{tabular}{|c|c|}
\hline Dimension & Definition \\
\hline $\begin{array}{l}\text { D1: Create continuous learning } \\
\text { opportunities }\end{array}$ & $\begin{array}{l}\text { Learning is designed into work so that } \\
\text { people can learn on the job; } \\
\text { opportunities are provided for ongoing } \\
\text { education and growth. }\end{array}$ \\
\hline $\begin{array}{l}\text { D2: Promote inquiry and } \\
\text { dialogue }\end{array}$ & $\begin{array}{l}\text { People gain productive reasoning skills } \\
\text { to express their views and the capacity } \\
\text { to listen and inquire into the views of } \\
\text { others; the culture is changed to support } \\
\text { questioning, feedback, and } \\
\text { experimentation. }\end{array}$ \\
\hline $\begin{array}{l}\text { D3: Encourage collaboration } \\
\text { and team learning }\end{array}$ & $\begin{array}{l}\text { Work is designed to use groups to } \\
\text { access different modes of thinking; } \\
\text { groups are expected to learn together } \\
\text { and work together; collaboration is } \\
\text { valued by the culture and rewarded. }\end{array}$ \\
\hline $\begin{array}{l}\text { D4: Create systems to capture } \\
\text { and share learning }\end{array}$ & $\begin{array}{l}\text { Both high- and low-technology systems } \\
\text { to share learning are created and } \\
\text { integrated with work; access is } \\
\text { provided; systems are maintained. }\end{array}$ \\
\hline $\begin{array}{l}\text { D5: Empower people toward a } \\
\text { collective vision }\end{array}$ & $\begin{array}{l}\text { People are involved in setting, owning, } \\
\text { and implementing a joint vision; } \\
\text { responsibility is distributed close to } \\
\text { decision making so that people are } \\
\text { motivated to learn toward what they are } \\
\text { held accountable to do. }\end{array}$ \\
\hline $\begin{array}{l}\text { D6: Connect the organization } \\
\text { to its environment }\end{array}$ & $\begin{array}{l}\text { People are helped to see the effect of } \\
\text { their work on the entire enterprise; } \\
\text { people scan the environment and use } \\
\text { information to adjust work practices; } \\
\text { the organization is linked to its } \\
\text { communities. }\end{array}$ \\
\hline $\begin{array}{l}\text { D7: Provide strategic leadership } \\
\text { for learning }\end{array}$ & $\begin{array}{l}\text { Leaders model, champion, and support } \\
\text { learning; leadership uses learning } \\
\text { strategically for business results. }\end{array}$ \\
\hline
\end{tabular}




\section{KEY RESULTS}

Financial performance

Knowledge performance
State of financial health and resources available for growth

Enhancement of products and services because of learning and knowledge capacity (lead indicators of intellectual capital)

Before transition to learning organization, during and after the transition is possible to use the Dimensions of Learning Organization Questionnaire (DLOQ) to capture the employees' opinion and to find out whether is the process of transition to learning organization necessary or whether is the process successful. The DLOQ allows us to measure important changes in climate, culture, systems and structures of organization that affect whether individuals learn. The basis of the DLOQ is made up of seven dimensions and on performance outcomes (sensitive to learning) [4]. The full version of DLOQ consists of 43 questions but it is possible to use an abbreviated version of the original questionnaire with 21 items. The shorter version of DLOQ has reliability as same as the full version $[7,11]$.

The aim of this study is to find out how many IT organizations in the Czech Republic apply the learning organization concept and to suggest ways to make effective and competitive organization (transition to a learning organization).

\section{Methods}

The anticipated implementation of this study is during December 2017 - January 2018 and it will be realized as a questionnaire survey. For this study the shorter version of DLOQ (21 questions, 7 dimensions) will be used $[6,7]$. The dimensions will be measure on a 6-point Likert scale (Table 2). To ensure the validity of the questionnaire, translation to the Czech language and back-translation to English was performed by two independent translators. After that a pilot study was conducted to verify the understanding of the questionnaire. The pilot study was carried out among 20 students of combined form of engineer study of Information Management. After the pilot study, a final version of DLOQ was created by using the docs.google.com. Some additional information was added into the questionnaire (size of the organization, position in the organization). The respondents for this study were selected by company size (number of employees) and their focus (IT). Due to the lower representation of small and medium enterprises focused on IT, companies from all over the Czech Republic will be approached. The target number of respondents is approximately 300 .

The obtained data will be analyzed in the Microsoft Excel or IBM SPSS with use of non-parametric tests, alpha level 0.05 . 
Table 2. Example of 6-point Likert scale [7]

\begin{tabular}{lrllllll}
\hline Question & \multicolumn{3}{c}{$\begin{array}{c}\text { Almost } \\
\text { Never }\end{array}$} & & & $\begin{array}{c}\text { Almost } \\
\text { Always }\end{array}$ \\
\hline $\begin{array}{l}\text { In my organization, leaders } \\
\text { continually look } \\
\text { opportunities to learn. }\end{array}$ & for & 1 & 2 & 3 & 4 & 5 & 6 \\
\hline
\end{tabular}

\section{$3 \quad$ Results}

Given that this study is currently underway, the results of the pilot study are presented. The pilot study was attended by a total of 20 students (combined form of engineer study of Information Management). These respondents are active in the following spheres: software development, telecommunication, IT, electronics production, e-commerce, sales, law, healthcare, advertisement, state administration, work with kids, transport and logistics, sport and energy and heating.

The data from pilot study were analyzed using Microsoft Excel 2016.

The basic characteristics of respondents are shown in Table 3.

Table 3. The basic characteristics of respondents

\begin{tabular}{lcc}
\hline Gender & $\begin{array}{c}\text { Number of respondents } \\
(\mathbf{n = 2 0})\end{array}$ & $\begin{array}{c}\text { \% of respondents } \\
(\mathbf{n}=\mathbf{2 0})\end{array}$ \\
\hline Male & 11 & 55 \\
Female & 9 & 45 \\
\hline Age & & \\
\hline $21-30$ & 14 & 70 \\
$31-40$ & 4 & 20 \\
$41-50$ & 2 & 10 \\
& & \\
\hline Size of the organization & & 50 \\
\hline Up to 50 employees & 10 & 20 \\
Up to 250 employees & 4 & 5 \\
Up to 500 employees & 1 & 25 \\
More than 500 employees & 5 & \\
\hline Position in employment & & 65 \\
\hline Line worker & 13 & 35 \\
Boss & 7 & \\
\end{tabular}

Learning in relation to

work

0 hours per month

1

5 
1-10 hours per month

The answers of respondents were evaluated depending on seven dimensions of learning organization (Table 1). None of the dimensions were rated less than 3 points, from which we can conclude that organizations in the Czech Republic are in favor of learning support. The worst ratings got the dimensions number 4 (Create systems to capture and share learning), average score 3.70 and dimension 6 (Connect the organization to its environment), average score 3.90. The best rated dimension was dimension number 2 (Promote inquiry and dialogue), average score 4.67 (Figure 2).

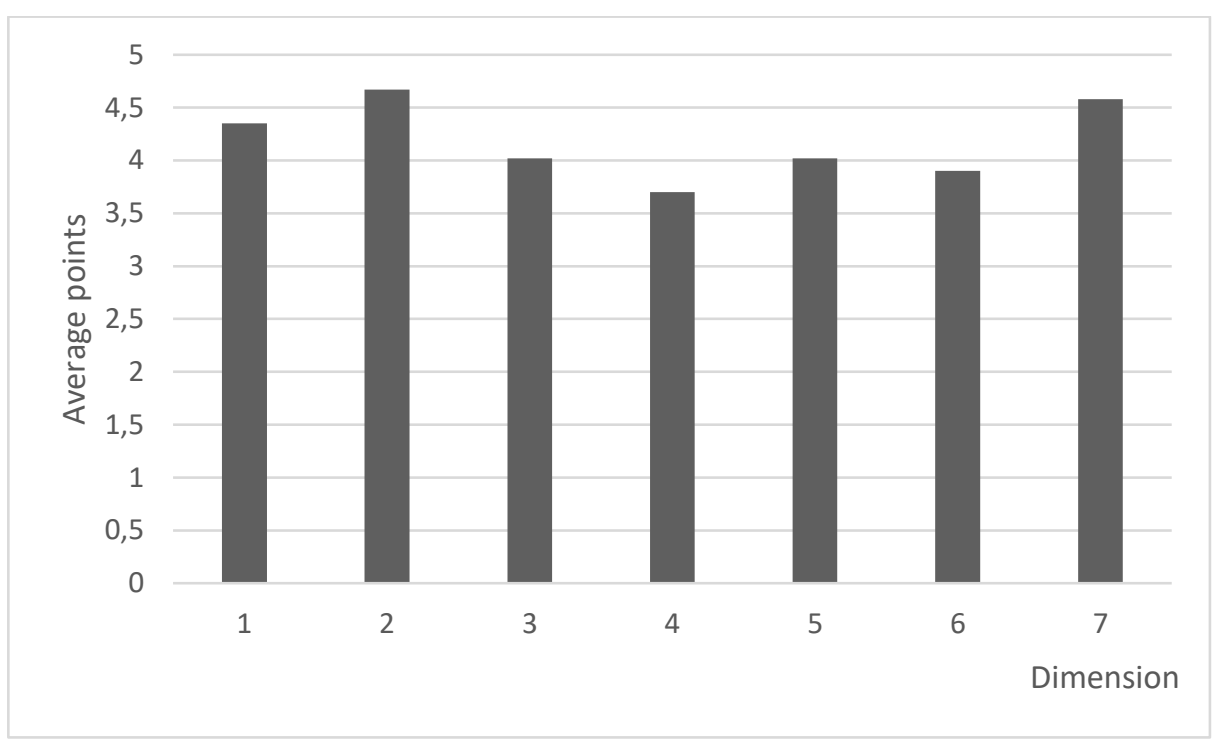

Fig. 2. Average points for seven dimensions of learning organization

When comparing dimensions between each other, there is a significant difference between the dimensions number 2 and 3 ( $p$ value at the alpha level 0.05 is 0.0015 ) and between the dimensions number 6 and 7 (p value at the alpha level 0.05 is 0.0022).

When compare the questions, more than 5 points was reached by two questions ( $\mathrm{n}$ $=21)$, the maximum points between 4 and 5 reached twelve questions $(n=21)$ and the minimum of 3 to 4 points reached only 7 questions.

There is no significant difference between the length of employment and the average score of concretely organization ( $p$ value at the alpha level 0.05 is 0.25 ). The maximum number of points was achieved by the company of more than 500 of employees (average score 5.62), the minimum number of points was achieved by the 
company of 251 to 500 employees (average score 3.0). Three organizations (sector healthcare, software development and the state administration) reached only $2.71-$ 3.00 points and their employees stated, that they spend less than 10 hours of learning per month.

\section{Discussion and Conclusions}

The situation concerning learning organizations in the Czech Republic is according the results of the pilot study quite good. The low rating of some criteria can be explained by the relatively high variability of respondents participating in the study. It is necessary to take account that the pilot study was conducted across different sectors and therefore the results of certain sectors can be different.

Surprising results have been achieved with specific organizations when three organizations from healthcare, state administration and software development spheres were rated less than 3 points. It needs to be considered, that other respondents from the same sectors rated their organizations with higher score. This can be justified by the fact that respondents came from different organizations. Another explanation is based on the relationship between the worker and the environment and on education. If the worker is uncommunicative and is not involved into the run of the company, it's hard for him to work in a team and support the learning organization.

All the low ratings came from the line workers and it is likely that the answers would be different if the same questions were answered by managers. Therefore, specific companies will be in the future research marked at the questionnaire and for each company will be obtained the results from two points of view - from the view of line workers and from the view of managers. This allows to obtain an objective assessment of each organization. For more representative results will be this study repeated at the larger sample and across one sector - concretely from the CZ-NACE sector 62 Activities in the field of information technologies and 63 Information activities.

Acknowledgements. The paper was written with the support of the Specific project 2018 granted by the University of Hradec Králové, Czech Republic.

\section{References}

1. Crossan, M. M., Lane, H. W., White, R. E.: An Organizational Learning Framework: From Intuition to Institution. Academy of Management Review 24(3), $522-537$ (1999).

2. Fiol, M. C., Lyles, M. A.: Organizational Learning. The Academy of Management Review 10(4), 803-813 (1985).

3. Hrabalová, S., Klímová, V., Nunvářová, S.: Metody a nástroje řizení ve veřejné správě. Masarykova univerzita v Brně, Brno (2005). 
4. Jamali, D., Sidani, Y., Zouein, Ch.: The learning organization: tracking progress in a developing country: A comparative analysis using the DLOQ. The Learning Organization 16(2), 103-121 (2009), DOI: 10.1108/09696470910939198.

5. Khosrov, N., Zaidatol, A. L. P.: Assessing Learning Organization Dimensions and Demographic Factors in Technical and Vocational Colleges in Iran. International Journal of Business and Social Science 3(3), 210-219 (2012).

6. Leufvén, M., Vitrakoti, R., Bergström, A., Ashish, KC., Mälqvist, M.: Dimensions of Learning Organizations Questionnaire (DLOQ) in a low-resource health care setting in Nepal. Health Research Policy and Systems 13(6) (2015), DOI: 10.1186/1478-4505-13-6.

7. Marsick, V. J., Watkins, K. E.: Demonstrating the Value of an Organization's Learning Culture: The Dimensions of the Learning Organization Questionnaire. Advances in Developing Human Resources 5(2), 132-151 (2003), DOI: $10.1177 / 1523422303251341$.

8. Norashikin, H., Amnah, M., Fauziah, N., Noormala, A. I.: Learning Organization and its Effect on Organizational Performance and Organizational Innovativeness: A Proposed Framework for Malaysian Public Institutions of Higher Education. Procedia - Social and Behavioral Sciences 130, 299-304 (2014), DOI: 10.1016/j.sbspro.2014.04.035.

9. Ropes, D., Thölke, J.: Communities of Practice: Finally a Link Between Individual and Organizational Learning in Management Development Programs. In: European Conference on Intellectual Capital 2010, Lisbon, Portugal (2010).

10. Senge, P. The Fifth Discipline: The Art and Practice of the Learning Organization. Management Press, Prague (2009).

11. Watkins, K. E., O'Neil, J.: The Dimensions of the Learning Organization Questionnaire (the DLOQ): A Nontechnical Manual. Advances in Developing Human Resources 15(2), 133-147 (2013), DOI: 10.1177/1523422313475854.

12. Yu Kyoung, P., Ji Hoon, S., Seung Won, Y., Jungwoo, K.: Learning organization and innovative behaviour: The mediating effect of work engagement. European Journal of Training and Development 38(1/2), 75-94 (2014), DOI: 10.1108/EJTD-04-2013-0040. 